\title{
METALLIC INTRAOCULAR FOREIGN BODY REMOVAL BY MAGNET V/A TRANS SCLERAL PARS PLANA APPROACH
}

\author{
Manzoor A. Qureshi, Shafi Muhammad Jatoi, Siddiqa Gul and Nazir Ashraf Laghari
}

\begin{abstract}
A young man working in a workshop sustained penetrating injury to his left eye and reported within 12 hours to Eye Hospital. Plain X-ray orbit confirmed the presence of intraocular foreign body near pars plana. Corneal wound of entry was repaired with 10/0 suture. The intraocular foreign body was removed by magnet through trans scleral magnet via pars plana approach without 3 port vitrectomy procedure. Mild traumatic endophthalmitis was controlled by intravitreal injection of Vancomycin $1 \mathrm{mg} / 0.1 \mathrm{ml}$, along with topical antibiotic and steroid therapy. After 6 weeks, extraction of soft traumatic cataract and posterior chamber lens implantation was done. Best-corrected vision of 6/12 was achieved.
\end{abstract}

KEY WORDS: Eye. Penetrating Injury. Foreign Body. Traumatic Lens. Magnetic Extraction.

\section{INTRODUCTION}

Penetrating ocular trauma with a retained intraocular foreign body is a severe injury with poor prognosis. ${ }^{1}$ Intraocular foreign bodies have received a great deal of attention by Ophthalmologists over the past three decades. ${ }^{2}$ Toxicity of intraocular foreign body is variable. Metallic ion poisoning of intraocular epithelial structures is seen with copper, iron, lead, zinc and nickel. ${ }^{3-5}$ Iron and copper have the greatest potential for metallosis. ${ }^{5}$ Management of an intraocular foreign body begins with accurate diagnosis. Most intraocular foreign bodies are metallic and magnetic. ${ }^{2,6}$ Magnetic removal of ferrous intraocular foreign body has been used for more than 100 years, but it has been criticized lately for causing more complications in comparison to vitrectomy. However, it still has a place in treating selected cases. ${ }^{1,7}$ The main advantages of magnet over vitrectomy are that the technique is relatively simple to perform, and it traumatizes vitreous body less than vitrectomy. ${ }^{7}$ The removal of intraocular foreign body with an electromagnet via transcleral pars plana approach in the case being reported was an elegant procedure because the intraocular foreign body $(<2 \mathrm{~mm})$ was conveniently located in the anterior vitreous near at pars plana and the magnet exerted no vitreous traction. Therefore, the conventional magnet extraction in an emergency is a viable treatment option in selected cases where the modern facility of vitrectomy is not available. The availability of modern technique of vitrectomy through pars plana is the standard method for the management of intraocular for- eign body. ${ }^{8}$ Moreover, the combining cataract surgery and intraocular lens implantation with vitrectomy in patient with traumatic cataract and intraocular foreign body reduce the number of surgical interventions and allow faster visual rehabilitation. ${ }^{9}$

\section{CASE HISTORY}

A 20 years old young man was working in a workshop without wearing protective goggles when he suffered a sharp blow to his left eye in 2005. He attended Eye Hospital within 12 hours of injury with moderate ocular pain. On examination, there was redness, photophobia, watering and the visual acuity was hand movement in affected eye. There was penetrating wound of $2 \mathrm{~mm}$ size at supero-temporal area of cornea with shallow anterior chamber and lens matter in pupillary area (Figure I). Fundus view was not visible. A limbal ring was applied, plain x-ray of orbit was obtained in different directions of gaze and intraocular foreign body was localized in the anterior part of vitreous body near pars plana at 6-7 O clock position (Figures II a and b). A and B scan ultrasound were also done to confirm the location of intraocular foreign body and intactness of chorio-retinal profile (Figure III). The corneal wound was repaired by $10 / 0$ nylon suture. A trans scleral incision of $2 \mathrm{~mm}$ was given and a trans scleral magnet was used for extraction of intraocular foreign body through pars plana (Figure IV). The size of extracted foreign body was $<2 \mathrm{~mm}$. Post-operative treatment of intravitreal injection of Vancomycin $1 \mathrm{mg} / 0.1 \mathrm{ml}$ was given, along with topical antibiotic and 
steroid therapy to control inflammation. After 6 weeks, patients' eye was quite. An ultrasound examination was performed to assess the intactness of chorioretinal profile. Biometry and intraocular lens (IOL) power were measured. Simple irrigation and aspiration of soft traumatic cataract was done by standard corneo-scleral limbal incision; posterior chamber IOL was implanted and incision closed by continous 10/0 nylon suture. During procedure, there was no vitreous prolapse and the rent in posterior capsule was small and sealed. Short course of combined topical antibiotic and steroid was given. Best corrected visual acuity 6/12 was checked (Figure V). This case was well without any complication after 3 month follow-up.

FIGURE I:

LEFT EYE TRAUMATIC INJURY SHOWS WOUND OF ENTRY AT SUPERO-TEMPORAL PART OF CORNEA WITH TRAUMATIC CATARACT ALONG WITH SYNAECHE

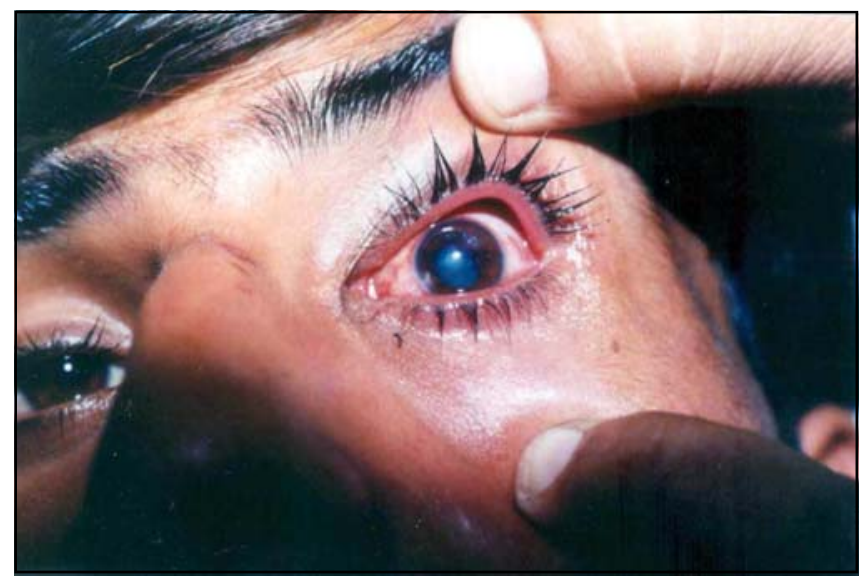

FIGURE II (a):

FRONT VIEW OF X-RAY ORBIT WITH LIMBALRING SHOWS INTRAOCULAR FOREIGN BODY (IOFB) NEAR PARS PLANA

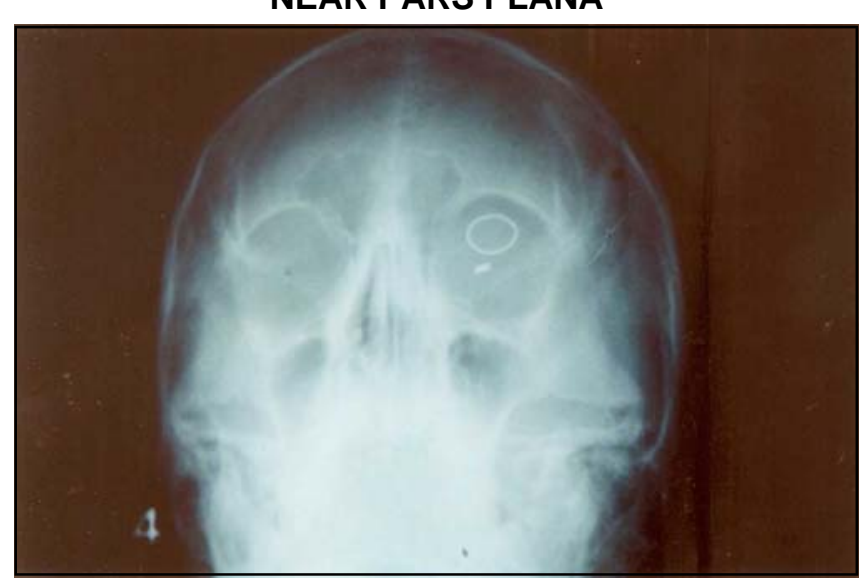

FIGURE II (b):

LATERAL VIEW OF X-RAY ORBIT SHOWS INTRAOCULAR FOREIGN BODY

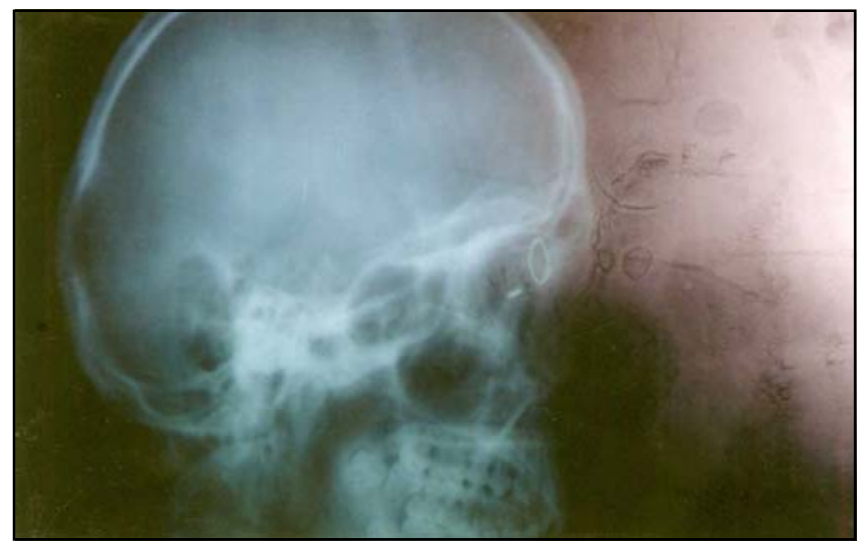

FIGURE III:

LEFT EYE ULTRASOUND A AND B SCAN SHOWS IOFB WITH INTACTNESS OF POSTERIOR

CHAMBER

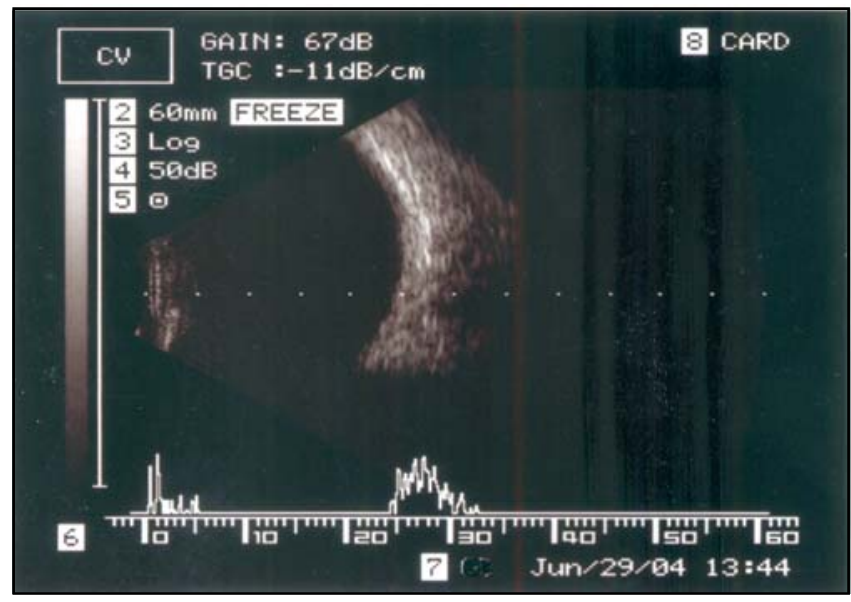

FIGURE IV:

IOFB REMOVAL BY EXTERNAL TRANS SCLERAL MAGNET VIA PARS PLANA APPROACH

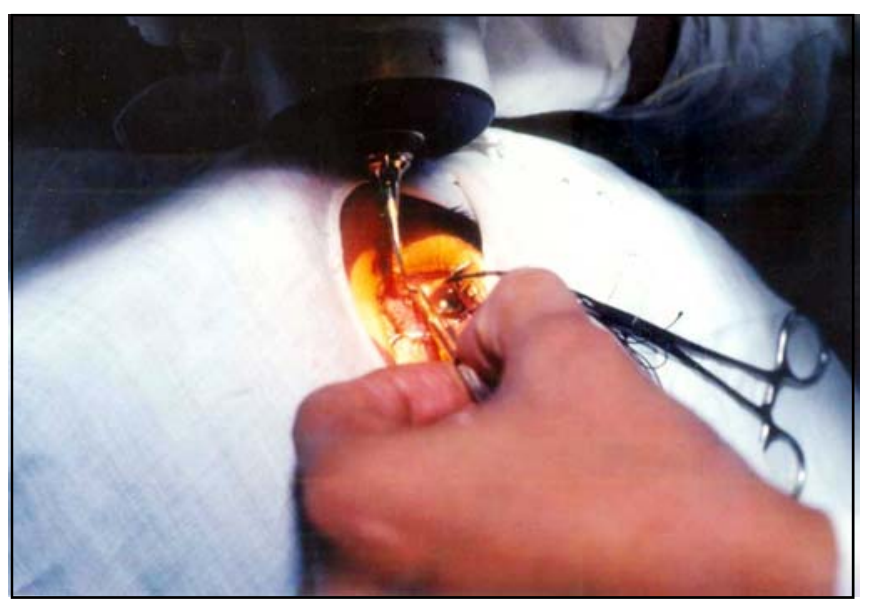


Manzoor A. Qureshi, Shafi Muhammad Jatoi, Siddiqa Gul, et al.

FIGURE V:

POST SURGICAL PRESENTATION OF EYE AFTER SIX WEEKS

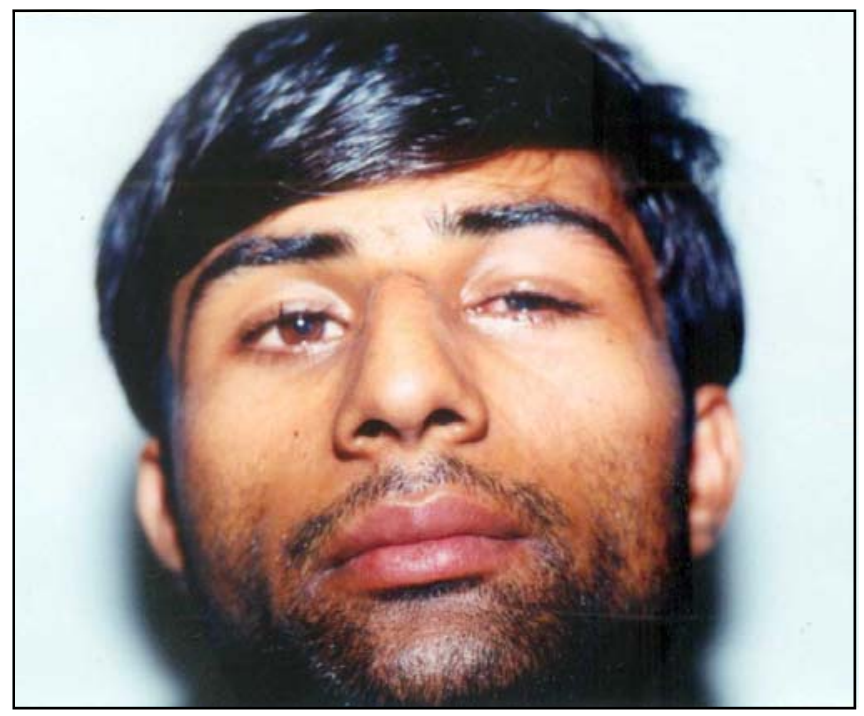

\section{DISCUSSION}

Penetrating ocular trauma with a retained intraocular foreign body is a severe injury with poor prognosis. ${ }^{1}$ Computerized tomography is the best method of localization, but a foreign body can also be missed on it, so a plain $\mathrm{x}$-ray is still the best method of detection. ${ }^{10}$ In this case, the presence of intraocular foreign body was confirmed with plain x-ray. Intraocular foreign bodies are removed through the limbus, pars plana, or posterior sclera. ${ }^{11-12}$ The proper route of extraction is determined by foreign body location, composition and associated ocular injuries. Pars plana vitrectomy is the leading method for the management of intraocular foreign bodies. ${ }^{8-13}$ The external approach of magnetic intraocular foreign body removal remains a viable treatment option in selected cases. ${ }^{1}$ But, in our case the intraocular foreign body was lying close to the pars plana, therefore, its removal was achieved by magnet via pars plana approach. The removal of intraocular foreign body with an electromagnet extraction in this case was an elegant procedure because the intraocular foreign body had developed mild traumatic inflammation, it was conveniently located near pars plana and magnet exerted no vitreous traction. The mild inflammation was controlled by intravitreal injection of Vancomycin $1 \mathrm{mg} / 0.1 \mathrm{ml}$, along with topical antibiotic and steroid therapy. After 6 weeks, when eye became quite, the plain irrigation and aspiration of soft traumatic cataract was done through standard limbal inci- sion and posterior chamber IOL was implanted. The best corrected visual acuity of 6/12 was achieved as there was no additional factor predictive of a poor visual acuity outcome such as intraocular foreign body larger than $3 \mathrm{~mm}$, the presence of vitreous haemorrhage, retinal detachment or severe traumatic

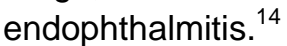

\section{REFERENCES}

1. Chow DR, Garretson BR, Kuczynski B, Williams GA, Margherio R, Cox MS, et al. External versus internal approach to the removal of metallic intraocular foreign bodies. Retina. 2000; 20:364-9.

2. Percival SPB. A decade of intraocular foreign bodies. Br J Opthamol. 1972; 56: 454.

3. Archer DB. Injuries of the posterior segment of eye, Dermot Pierse Lecture. Trans Opthalmol Soc UK. 1985; 104:597.

4. Schmidt JGH, Max M. Surface area sizes of intravitreal iron wires: their effects on the electro retinogram of rats. Ophthalmologica. 1988; 67: 263.

5. Soheilian $M$, Abolhasani A, Ahmadieh $H$, Azarmina $M$, Dehgan $M H$, Mashavekhi $A$, et al. Management of magnetic intravitreal foreign bodies in 71 eyes. Ophthalmic Surg Lasers Imaging. 2004; 35:372-8.

6. Welch RB. Two remarkable events in the field of intraocular foreign body: (1) the reversal of siderosis bulbi, (2) the spontaneous extrusion of an intraocular copper foreign body. Trans Am Ophthalmol Soc.1976; 73:187.

7. De Souza S, Howcroft MJ. Management of posterior segment intraocular foreign bodies; 14 years experience. Can J Ophthalmol. 1999; 34:23-9.

8. Mester V, Kuhn F. Ferrous intraocular foreign bodies retained in the posterior segment: management options and results. Int Ophthalmol. 1998; 22:355-62.

9. Tyagi $A K$, Kheterpal $S$, Callere $A B$, Kirby $G R$, Price NJ. Simultaneous posterior chamber in trasocular lens implant combined with vitreo-retinal surgery for intraocular foreign body injuries. Eye. 1998; 12:230-3.

10. Hadden OB, Wilson JL. The management of intraocular foreign bodies. Aust NZ J Ophthalmol.1990; 18:343-51.

11. Bencic G, Vatavuk Z, Mandic Z. Novel approach 
in the treatment of intravitreal foreign body and traumatic cataract. CMJ. 2004; 45:283-6.

12. Michels RG. Surgical management of nonmagnetic intraocular foreign body. Arch Ophthalmol. 1975; 93:1003.

13. Peyman GA, Raichand M, Goldberg MF, Brown S. Vitrectomy in the management of intraocular for- eign bodies and their complications. $\mathrm{Br} \mathrm{J}$ Opthalmol. 1980; 64:476-82.

14. Greven CM, Engelbrecht NE, Slusher MM, Nagy SS. Intraocular foreign bodies: management, prognostic factors and visual outcomes. Ophthalmology. 2000; 107:608-12.

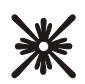

AUTHOR AFFILIATION:

Dr. Manzoor A. Qureshi (Corresponding Author) Assistant Professor

Liaquat University Eye Hospital, Hyderabad - Sindh.

E-mail: drmaqureshi@hotmail.com

Prof. Shafi Muhammad Jatoi

Liaquat University Eye Hospital, Hyderabad - Sindh.

Dr. Siddiqa Gul

Resident

Liaquat University Eye Hospital, Hyderabad - Sindh.

Prof. Nazir Ashraf Laghari

Liaquat University Eye Hospital, Hyderabad - Sindh. 